\title{
Effect of Urea on the Conformation and Chain Flexibility of Chitosan Molecules with Various Degree of Deacetylation
}

\author{
Rong Huei Chen \\ Department of Marine Food Science, National Taiwan Ocean University Keelung 20224, Taiwan, Republic of China \\ Jeun Hwang Lin \\ Department of Marine Food Science, National Taiwan Ocean University Keelung 20224, Taiwan, Republic of China \\ Toshiro Tsaih \\ Department of Marine Food Science, National Taiwan Ocean University Keelung 20224, Taiwan, Republic of China
}

Follow this and additional works at: https://jmstt.ntou.edu.tw/journal

Part of the Aquaculture and Fisheries Commons

\section{Recommended Citation}

Chen, Rong Huei; Lin, Jeun Hwang; and Tsaih, Toshiro (1994) "Effect of Urea on the Conformation and Chain Flexibility of Chitosan Molecules with Various Degree of Deacetylation," Journal of Marine Science and Technology. Vol. 2: Iss.

1, Article 1.

DOI: $10.51400 / 2709-6998.2482$

Available at: https://jmstt.ntou.edu.tw/journal/vol2/iss1/1

This Research Article is brought to you for free and open access by Journal of Marine Science and Technology. It has been accepted for inclusion in Journal of Marine Science and Technology by an authorized editor of Journal of Marine Science and Technology. 


\section{Effect of Urea on the Conformation and Chain Flexibility of Chitosan Molecules with Various Degree of Deacetylation}

Acknowledgements

The authors wish to express their appreciation for the financial support from the National Science Council, Republic of China. (Project No: NSC 81-0409-B-019-508) 


\title{
EFFECT OF UREA ON THE CONFORMATION AND CHAIN FLEXIBILITY OF CHITOSAN MOLECULES WITH VARIOUS DEGREE OF DEACETYLATION
}

\author{
Rong Huei Chen, Jeun Hwang Lin and Toshiro Tsaih \\ Department of Marine Food Science, National Taiwan Ocean University \\ Keelung 20224, Taiwan, Republic of China
}

\begin{abstract}
Key words: chitosan, urea, conformation, chain flexibility, degree of deacetylation.
\end{abstract}

\begin{abstract}
Chitosans with various degrees of deacetylation (DD) were prepared from red shrimp (Solenocera prominentis). DD of chitosan was determined by infrared spectrum. The effect of urea on the conformation and chain flexibility of chitosan molecules with various DD was studied. The results show: 1) The intrinsic viscosities of chitosan solutions containing $4 \mathrm{M}$ urea were higher than those without urea addition. It indicated the chitosan molecules in solutions containing urea have higher hydrodynamic volume than that without urea. It may due to urea increasing the intramolecular hydrogen bond formation. 2) The persistence lengths of chitosan molecules were longer in solutions containing $4 \mathrm{M}$ urea than that without urea addition. The results indicated the molecules were more extend in solutions containing urea than that without urea. 3) Addition of $4 \mathrm{M}$ urea to chitosan solutions rendered the Smidsrod chain stiffness parameters lower than that without urea addition. It indicated that the possible attribute of degree of polymerization on the persistence length may be rule out.
\end{abstract}

\section{INTRODUCTION}

Lin (1974) revealed the effect of urea on the rheological properties of chitosan solution. Rheological properties of solutions are affected by hydrodynamic volume of solute which are in term affected by conformation, chain flexibility, molecular weight of the solute. Although, studies on the effect of solvent properties ( $\mathrm{pH}$, ionic strength, counter ion), of shear rate, and temperature on the rheological properties of chitosan are numerous. However, studies on the effect of urea on the rheological properties of chitosan are relatively rare. Report on the effect of urea on conformation and chain flexibility of chitosan molecule are even rare.

Persistence length (Rinaudo and Domard, 1989; Rinaudo et al., 1993; Kienzle-Sterzer et al., 1984), Smidsrod's stiffness parameter (Rinaudo and Domard, 1989; Rinaudo et al., 1993; Terbojevich et al., 1986), characteristic ratio (Kienzle-Sterzer et al., 1984; Anthonsen et al., 1993), Kuhn statistical segment length (Kienzle-sterzer et al., 1986; Berkovich et al., 1980;
Lyubina et al., 1983; Pogodina et al., 1986) have been used to characterize the stiffness of molecule. The MarkHouwink exponent parameter, " a ", has been used as a molecular conformation parameter. "a" value higher than 0.8 , the molecule is a rod shape, "a" value in $0.5-0.8$, the molecule is in random coil, " a " value below 0.5 , the molecule is very compact globular. " $a$ " values of chitosans in different solutions range between 0.17-0.8. It indicates the conformation of chitosans range from random coil, quasi globular and rod shape and depend on the solution conditions (Kienzle-Sterzer et al., 1986; Berkovich et al., 1980; Errington et al., 1993). KienzleSterzer et al. (1986) reported the conformation of chitosan is an extended coil with Kuhn statistical segment of $12.16 \mathrm{~nm}$ in the presence of urea. Whereas, it is in a compact structure with a Kuhn statistical segment of 7.28 $\mathrm{nm}$ without urea. Mark-Houwink exponent " a " value is about 0.147 in $1 \%$ acetic/ $2.8 \% \mathrm{NaCL}$ without urea, change to about 0.71 when urea is present. (KienzleSterzer et al., 1986). Sklyar et al. (1981) reported the addition of $4 \mathrm{M}$ to $8 \mathrm{M}$ urea prevents the reduction of 
solution viscosity on standing. The reduction was more pronounced in solutions that are lower concentration of acid in the solvent or higher concentration of the solute in solution. The reduction in solution viscosity may due to intramolecular hydrogen bonds. Frangou et al. (1982) reported the effect of urea on the stabilization of the ordered conformation of xanthan perhaps by reduction in water activity of solution.

The objective of the studies are to explore the effect of urea on the conformation and chain stiffness of chitosans with various degree of deacetylation.

\section{MATERIALS AND METHODS}

\section{1) Preparation of chitin}

The chitin was prepared by the modified method of Stanley et al. (1976) and Lai (1979). Ground shell and head of red shrimp (Solenocera prominentis) were soaked in $0.5 \mathrm{~N} \mathrm{NaOH}$ solution at room temperature overnight to remove the surface meat. Washed with water, dried, comminuted the dried product to pass through the 60 mesh sieve. Soaked the powder in $2 \mathrm{~N} \mathrm{HCl}$ to remove the minerals, at the same time $\mathrm{CO}_{2}$ was removed by suction till no further $\mathrm{CO}_{2}$ was detected. Washed then soaked in $2 \mathrm{~N} \mathrm{NaOH}$ at $80^{\circ} \mathrm{C}$ for $1 \mathrm{~h}$ to hydrolyze the protein. The de-proteined powder was washed then soaked in $1 \%$ $\mathrm{K}_{2} \mathrm{MnO}_{4}$ at room temperature for $1 \mathrm{~h}$ to remove astaxanthin. Washed then soaked in $1 \%$ oxalic acid at room temperature to remove excess of $\mathrm{K}_{2} \mathrm{MnO}_{4}$ then washed, dried to get chitin.

\section{2) preparation of chitosan of various DD}

Soaked the chitin in $11 \%, 40 \%$ and $50 \% \mathrm{NaOH}$ (v/w) at $45^{\circ} \mathrm{C}, 95^{\circ} \mathrm{C}, 110^{\circ} \mathrm{C}$, and $140^{\circ} \mathrm{C}$ for 0.5 to $10 \mathrm{~h}$. The alkali treated solutions were washed with water and dried to get chitosans of various DD (Chen et al., 1994a, 1994b).

\section{3) The determination of the DD}

Infrared spectrometry method reported by Domszy and Roberts (1985); Moore and Roberts (1980); Sannan et al. (1976) was used to determine the degree of $\mathrm{N}$ acetylation of the chitosan. Powder of chitosan was mixed with $\mathrm{KBr}(1: 100)$ and pressed into pellet. The absorbencies of amide $1\left(1655 \mathrm{~cm}^{-1}\right)$ and of hydroxyl band (3450 $\mathrm{cm}^{-1}$ ) were measured by Hitachi 260-30 infrared spectrophotometer. The band of hydroxyl group at $3450 \mathrm{~cm}^{-1}$ was used as an internal standard to correct for film thickness or for difference in chitosan concentration in making $\mathrm{KBr}$ disc. The percentage of the amine group's acetylation in a sample was given by (A1655/A3450) $x$ 115. Here A1655, A3450 are absorbencies at 1650 $\mathrm{cm}^{-1}$ and $3450 \mathrm{~cm}^{-1}$ respectively.

\section{4) Intrinsic viscosity determination}

Cannon-Fenske capillary viscometer was used to measure the pass time of solution flow through the capillary. The solutions were prepared by different $\mathrm{pH}(\mathrm{pH}$ 3 to $\mathrm{pH} 5$ ), different ionic strength (0.M to $0.6 \mathrm{M}$ ), and different DD chitosans $(80,90$, and $100 \%)$. The pHs of chitosan solutions were controlled by dissolving the chitosans of various DD in $\mathrm{pH} 3$ acetic acid then adjusted the solutions' $\mathrm{pH}$ to $\mathrm{pH} 4$ or 5 with $\mathrm{NaOH}$. The ionic strengths were adjusted by adding $\mathrm{NaCl}$ to the designated molarity. The capillary viscometer was filled with 5 $\mathrm{ml}$ of sample and equilibrated in water bath (Tampson, TMV40, Holland) at preseted temperature $\pm 0.1^{\circ} \mathrm{C}$ for 15 min. The sample was passed through the capillary once before running time was measured. The running time was used to calculate the relative viscosity, then reduced viscosity. Plot the reduced viscosity against the concentration. The intercept is the intrinsic viscosity (Chen et al., 1994a; 1994b).

\section{5) The persistence length of chitosan molecule}

The persistence length is the projection of the end to end distance on the direction of the first bond. The persistence length of chitosan in dilute solution was estimated according to the method of Modified Yamakawa and Fujii (1974) by using the following equation.

$$
[\eta]=\phi\left(2 \mathrm{P}_{\mathrm{L}} / \mathrm{M}_{\mathrm{L}}\right)^{3 / 2}\left(\mathrm{M}_{\mathrm{w}}\right)^{1 / 2}
$$

Here, $[\eta]$ is the intrinsic viscosity; $\phi$ is the Flory constant and equal to $2.3 \times 10^{23}$ when $[\eta]$ is in $\mathrm{cm}^{3} / \mathrm{g} ; \mathrm{P}_{\mathrm{L}}$ is the overall persistence length; $M_{L}$ is the mass per unit length and relates to molecular weight and contour length of solute as $M_{L}=M_{w} / L$. Mw and $L$ are the molecular weight and the contour length of the solute respectively. Lequals to $\left(M_{w} / m_{0}\right)$ l. Here, mo is molecular weight of monomer; 1 is the length of monomer, it is 5.33 $\AA$ for glucosamine.

\section{6) Smidsrod's stiffness parameter}

The slope $S$ of the linear dependent between intrinsic viscosity, $[\eta] \mathrm{u}$ and the molar salt concentration, $\left(\mathrm{C}_{\mathrm{s}}\right)^{-1 / 2}$ is related to the stiffness of the molecule (Smidsrod and Huag, 1971). They have obtained the following empirical relationship

$$
\mathrm{S}=\mathbf{B}\left([\eta]_{0.1 \mathrm{M}}\right)^{\mathbf{v}}
$$

Here, $B$ is an empirical stiffness parameter, $v$ is an exponent between 1.2 and 1.4. Then, the logarithm slope $\mathrm{S}$ are plotted against the logarithm intrinsic viscosity in 
$0.1 \mathrm{M}$ salt concentration, $[\mathrm{h}]_{0.1} \mathrm{M}$. The intercept is the $\mathrm{B}$ value

\section{RESULTS}

\section{1) Effect of ionic strength on the intrinsic viscosity of different $\mathrm{pH}$ chitosan solutions}

In general, intrinsic viscosities decreased with increasing ionic strength between $0 \mathrm{M}$ to $0.05 \mathrm{M} \mathrm{NaCl}$ then intrinsic viscosities increased as ionic strength continuous increasing to $0,6 \mathrm{M}$ for three chitosans and $\mathrm{pHs}$ studied. The ionic strength dependency of intrinsic viscosity was due to the polyelectrolyte effect. The polyelectrolyte effect of $\mathrm{pH} 3$ solutions were more pronounced than that of $\mathrm{pH} 4$ or $\mathrm{pH} 5$ solutions. In $\mathrm{pH} 3$, $80 \%$ DD chitosan solutions, the intrinsic viscosity decreased sharply from $15.4 \mathrm{dl} / \mathrm{g}$ to $5.6 \mathrm{dl} / \mathrm{g}$ as $\mathrm{NaCl}$ concentration increase to $0.05 \mathrm{M}$ from $0 \mathrm{M}$, then increased to $8.7 \mathrm{dl} / \mathrm{g}$ as $\mathrm{NaCl}$ further increase to $0.6 \mathrm{M}$. Different rates of reduction in intrinsic viscosities as $\mathrm{NaCl}$ concentration increase to $0.05 \mathrm{M}$ from $0 \mathrm{M}$ indicated the attributes of different DD (between 80-100\%). The effects of DD of chitosans also can be observed on different intrinsic viscosities measured from three chitosan solutions at the same ionic strength and $\mathrm{pH}$. The $80 \% \mathrm{DD}$ ones have the largest intrinsic viscosities, $90 \% \mathrm{DD}$ ones were the secondth and $100 \%$ ones were the smallest. The smallest value of $2.18 \mathrm{dl} / \mathrm{g}$ was observed from $100 \%$ DD chitosan in $\mathrm{pH} 5,0.05 \mathrm{M} \mathrm{NaCl}$ solution. The largest value of $15.4 \mathrm{dl} / \mathrm{g}$ was observed from $80 \%$ DD chitosan in $\mathrm{pH} \mathrm{3,0} \mathrm{M} \mathrm{NaCl}$ solution. The intrinsic viscosity reduction as $\mathrm{NaCl}$ increase to $0.05 \mathrm{M}$ from $0 \mathrm{M}$ were 15.4 to $5.6 \mathrm{dl} / \mathrm{g} ; 13.4$ to $4.5 \mathrm{dl} / \mathrm{g}$ and 9.0 to $3.5 \mathrm{dl} / \mathrm{g}$ for 80,90 , $100 \%$ DD chitosans respectively.

\section{2) The effect of $\mathrm{pH}$, ionic strength and $4 \mathrm{M}$ urea on the intrinsic viscosity of chitosan solutions}

Fig. 2 shown The trends of the changes (due to 1 . polyelectrolyte effect, 2. pH dependent, 3. DD of chitosan molecules) were overall similar to that shows in Fig. 1. but difference in absolute values. However, as $\mathrm{NaCl}$ concentration increasing to $0.6 \mathrm{M}$, intrinsic viscosities may be equal to or larger than that of $0 \mathrm{M} \mathrm{NaCl}$ ones. The smallest intrinsic viscosity of $11.9 \mathrm{dl} / \mathrm{g}$ was observed at solution of $100 \%$ DD chitosan in $\mathrm{pH} 5,0.05 \mathrm{M} \mathrm{NaCl}$ solution. Whereas, the largest intrinsic viscosity of $21.1 \mathrm{dl} /$ $\mathrm{g}$ was observed at $80 \% \mathrm{DD} \mathrm{pH} \mathrm{3,0} \mathrm{M} \mathrm{NaCl}$ solution. Reduction in intrinsic viscosities as $\mathrm{NaCl}$ increasing to $0.05 \mathrm{M}$ from $0 \mathrm{M}$ were 21.1 to $17.2 \mathrm{dl} / \mathrm{g}, 20.0$ to $17.8 \mathrm{dl} / \mathrm{g}$, and 17.1 to $17.08 \mathrm{dl} / \mathrm{g}$ for 80,90 , and $100 \%$ DD chitosans respectively.

\section{3) Effect of pH,ionic strength on the persistence length}
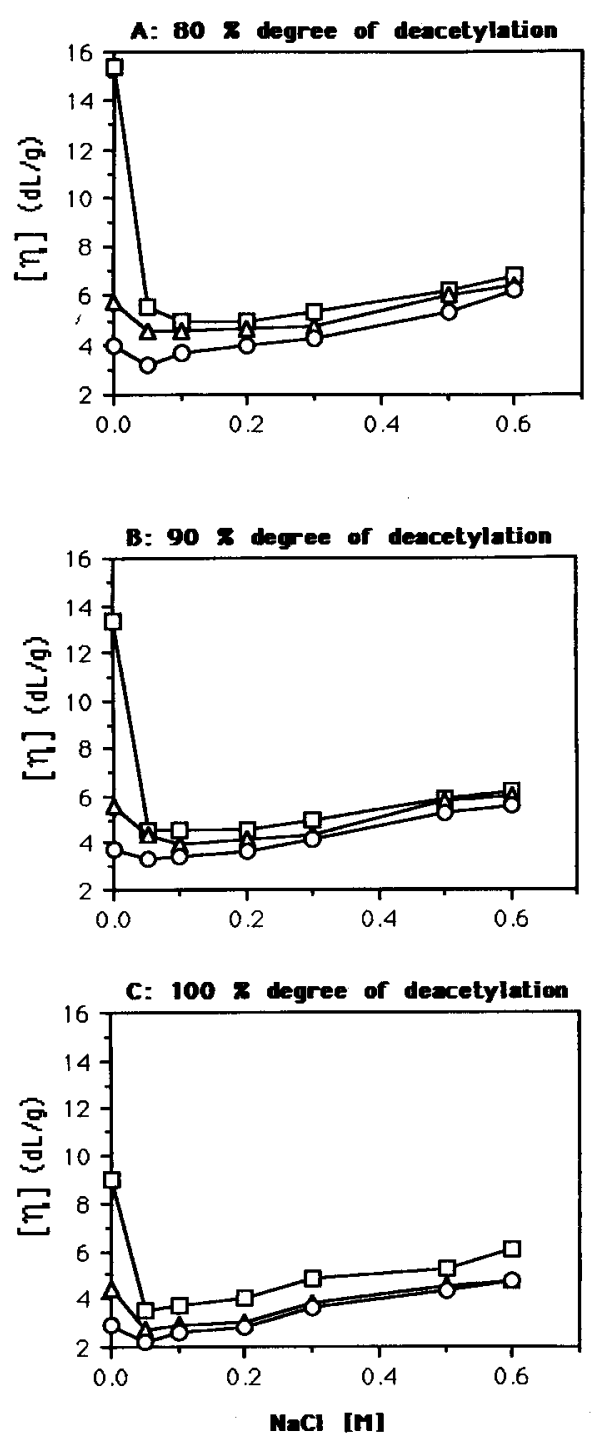

Fig. 1. Effect of degree of deacetylation, $\mathrm{pH}$, and ionic strength on intrinsic viscosity $(\mathrm{d} \mathrm{l} / \mathrm{g})$ of chitosan at $25.0 \pm 0.1^{\circ} \mathrm{C}$.

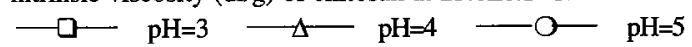

\section{of chitosan molecules with different DD}

Persistence lengths varied also with $\mathrm{pH}$, ionic strength, DD of chitosans (Table 1) that were similar to the results shown in Fig. 1. Persistence lengths decreased rapidly as ionic strength increasing from $0 \mathrm{M}$ to $0.05 \mathrm{M}$. The persistence lengths further increased steadily with increasing in ionic strength from $0.05 \mathrm{M}$ to $0.6 \mathrm{M}$. The smallest persistence lengths were observed at solutions of 0.05-0.1 $\mathrm{M} \mathrm{NaCl}$ in three $\mathrm{pHs}$ and chitosans studied. Persistence lengths changed also with DD of chitosan molecules between $\mathrm{pH} 3$ to $\mathrm{pH} 5$. The $80 \%$ DD chitosans have longer persistence lengths than those of $90 \%$ DD ones in term were longer than $100 \% \mathrm{DD}$ ones at the same $\mathrm{pH}$ and ionic strength. The persistence length also $\mathrm{pH}$ dependent and the longest ones were found in $\mathrm{pH} 3$ solutions. The decrease were proportional with increasing 
in solution $\mathrm{pH}$.

\section{4) Effect of $\mathrm{pH}$, ionic strength, $4 \mathrm{M}$ urea on persistence length of chitosan molecules with different DD}

Data in Table 1 shown the trends of the changes were similar to that shown in Fig. 2. Persistence lengths decreased with increasing ionic strength from $0 \mathrm{M}$ to 0.05 $M$ then increased as ionic strength increasing further to $0.6 \mathrm{M} \mathrm{NaCl}$. The changes were more pronounced for chitosans of $80 \%$ DD ones than that of $90 \%$ ones and also than that of $100 \% \mathrm{DD}$ ones. The effect of media $\mathrm{pH}$ were more pronounced in $\mathrm{pH} 3$ solutions than in $\mathrm{pH} 5$ solutions. Persistence lengths of chitosan molecules in solutions containing $4 \mathrm{M}$ urea were longer than that without $4 \mathrm{M}$ urea. The persistence lengths at $0.6 \mathrm{M}$ ones were longer than that at $0 \mathrm{M} \mathrm{NaCl}$ ones.

\section{5) The effect of pH, urea on Smidsrod's stiffness parameter}

Table 2 shown $\mathrm{B}$ values increased with increasing solution $\mathrm{pH}$ and/or with DD of chitosan molecules. B value of $80 \% \mathrm{DD}$ chitosan in $\mathrm{pH} 3$ solution was the smallest, 0.103 whereas, B value of $100 \%$ DD chitosan in $\mathrm{pH} 5$ solution was the largest, 0.291 in solutions without urea. The trends were similar to the solutions containing $4 \mathrm{M}$ urea. However, B value were smaller compared to those without urea addition. $\mathrm{B}$ value was 0.021 for $80 \%$ DD chitosan in $\mathrm{pH} 3$ solution and was 0.040 for $100 \% \mathrm{DD}$ chitosan in $\mathrm{pH} 5$ solution. The effect of $\mathrm{pH}$ on $\mathrm{B}$ value become less significant in solutions containing $4 \mathrm{M}$ urea.

\section{DISCUSSION}

\section{1) Effect of urea on intrinsic viscosity of chitosan}

Fig. 1. and 2. shows intrinsic viscosities of chitosans $(80-100 \% \mathrm{DD})$ ranged from $15.4 \mathrm{dl} / \mathrm{g}$ to $2.2 \mathrm{dl} / \mathrm{g}$ in different $\mathrm{pH}(\mathrm{pH} 3-5)$, different ionic strength $(0 \mathrm{M}$ to 0.6 $\mathrm{M} \mathrm{NaCl}$ ) solutions. The variation of intrinsic viscosity may due to different steric effect (caused by different DD), number of protonated amino group (by different solution $\mathrm{pH}$ ), and polyelectrolyte effect (by different solution ionic strength)Intrinsic viswsity ranged between 15.4 to $2.2 \mathrm{de} / \mathrm{g}$ and 21.1 to $11.8 \mathrm{dl} / \mathrm{f}$ for solutions with on without urea respectvely. Intivision viswsity ranged between 21-1.4 $\mathrm{dl} / \mathrm{g}$ urea respected in the light ature Anthonsen et al., 1993 gamzazade et al., 1981 for Chitosan solutions without urea addition. The effect of DD and lonic strength on untunsic viscosity were indicated by the reduction of intrinsic viscosity from 15.4 to $5.57 \mathrm{dl} / \mathrm{g}$, 13.4 to $4.52 \mathrm{dl} / \mathrm{g}$, and 9.0 to $3.5 \mathrm{dl} / \mathrm{g}$ for 80,90 , and $100 \%$ DD chitosan respectively as ionic strength increasing to $0.05 \mathrm{M}$ from $0 \mathrm{M} \mathrm{NaCl}$.
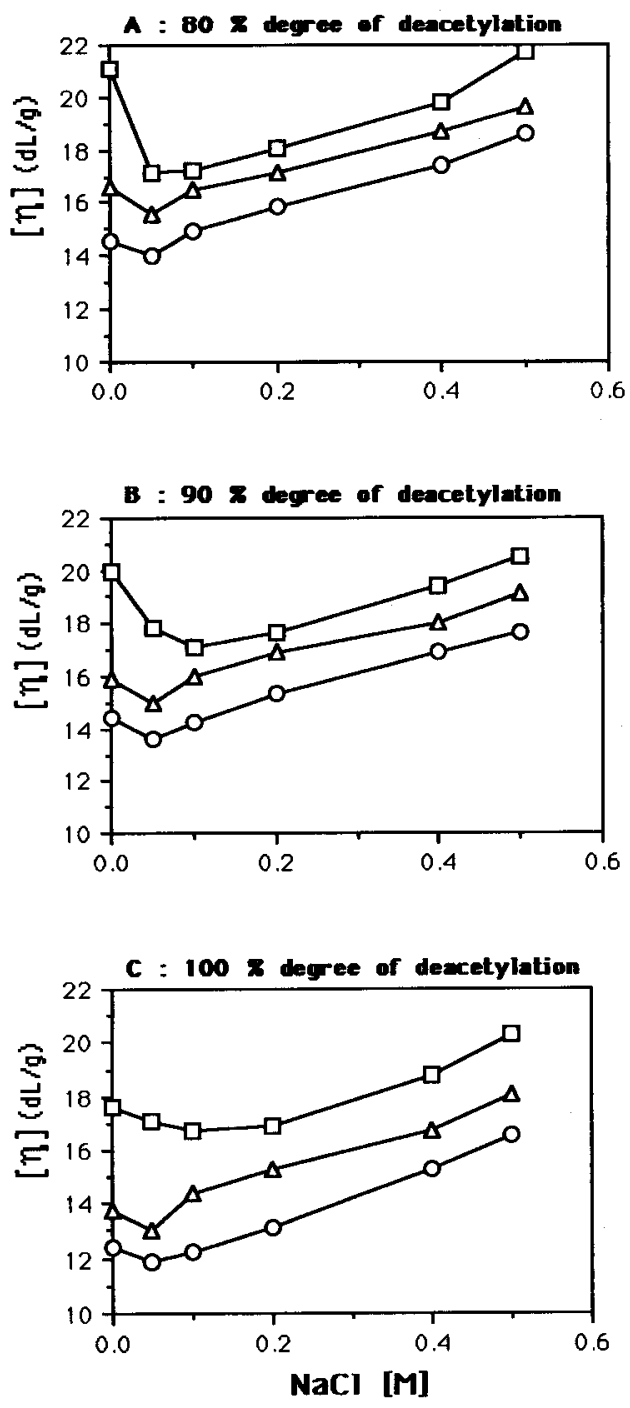

Fig. 2. Effect of $4 \mathrm{M}$ urea, degree of deacetylation, $\mathrm{pH}$, and ionic strength on intrinsic viscosity $(\mathrm{d} / \mathrm{g})$ of chitosan at $25.0 \pm 0.1^{\circ} \mathrm{C}$. $\longrightarrow \mathrm{pH}=3 \longrightarrow \mathrm{pH}=4 \longrightarrow \mathrm{OH}=5$

Similar results were reported by Wang et al.(1991), Rinaudo et al. (1993).

Urea addition rendered the chitosans solutions increasing in intrinsic viscosity. Gamzazade et al. (1981) reported similar results and revealed the intrinsic viscosities were around 21.0 and $25 \mathrm{dl} / \mathrm{g}$ in $2 \%$ acetic acid in the absence and presence of urea respectively. The increasing in intrinsic viscosity due to urea addition were $5.7 \mathrm{dl} / \mathrm{g}$ at $0 \mathrm{M} \mathrm{NaCl}$ (from 15.4 to $21.1 \mathrm{dl} / \mathrm{g}$ ) versus $9.7 \mathrm{dl} / \mathrm{g}$ at $0.05 \mathrm{M} \mathrm{NaCl}$ (from 2.2 to $11.9 \mathrm{dl} / \mathrm{g}$ ) (Figure 1 and 2). The increases at $0 \mathrm{M} \mathrm{NaCl}$ was not as significant as the increase at $0.05 \mathrm{M} \mathrm{NaCl}$. It indicated urea addition in-fluence less on the third electroviscous effect than on the first electroviscous effect. The increase in intrinsic viscosity may be also due to conformational change caused by urea. Since Kienzle-Sterzer et al. (1986) reported Mark-Houwink exponent parameter "a" of 0.14 and 0.71 in $1.0 \%$ acetic/ $20 \% \mathrm{NaCl}$ chitosan solution 
Table 1. Effect of degree of deacetylation, $\mathrm{pH}, 4 \mathrm{M}$ urea, and ionic strength on persistence length (A) of chitosans at $25.0+0.1 \mathrm{C}$.

\begin{tabular}{|c|c|c|c|c|c|c|c|}
\hline \multirow{2}{*}{$\begin{array}{c}\text { Degree of } \\
\text { decaetylation } \\
(\%)\end{array}$} & \multirow{2}{*}{$\begin{array}{c}{[\mathrm{NaCl}]} \\
(\mathrm{M})\end{array}$} & \multicolumn{3}{|c|}{$\mathrm{pH}$} & \multicolumn{3}{|c|}{ (4 M urea) } \\
\hline & & 3 & 4 & 5 & 3 & 4 & 5 \\
\hline 80 & 0.00 & 177.95 & 93.75 & 72.70 & 219.42 & 186.86 & 179.42 \\
\hline \multirow{6}{*}{ ou } & 0.05 & 90.37 & 79.53 & 61.58 & 191.40 & 179.77 & 167.28 \\
\hline & 0.10 & 83.91 & 78.65 & 68.70 & 192.09 & 186.33 & 174.59 \\
\hline & 0.20 & 83.65 & 79.93 & 72.18 & 198.09 & 190.88 & 181.66 \\
\hline & 0.30 & 88.00 & 81.37 & 75.50 & 210.19 & 202.45 & 193.13 \\
\hline & 0.50 & 97.10 & 95.60 & 87.95 & 224.10 & 208.87 & 201.67 \\
\hline & 0.60 & 103.77 & 99.47 & 97.69 & & & \\
\hline \multirow[t]{7}{*}{90} & 0.00 & 168.10 & 93.94 & 72.25 & 219.78 & 188.88 & 176.75 \\
\hline & 0.05 & 81.66 & 79.98 & 66.23 & 203.59 & 181.52 & 170.28 \\
\hline & 0.10 & 81.63 & 75.08 & 67.94 & 198.41 & 189.10 & 175.77 \\
\hline & 0.20 & 82.25 & 76.71 & 70.41 & 202.64 & 196.30 & 184.54 \\
\hline & 0.30 & 86.50 & 79.54 & 76.71 & 215.52 & 205.03 & 196.90 \\
\hline & 0.50 & 97.60 & 95.88 & 90.04 & 223.66 & 213.56 & 202.60 \\
\hline & 0.60 & 101.05 & 97.97 & 93.75 & & & \\
\hline \multirow[t]{7}{*}{100} & 0.00 & 137.41 & 85.37 & 65.07 & 215.38 & 182.32 & 170.55 \\
\hline & 0.05 & 73.77 & 62.09 & 53.46 & 210.86 & 175.84 & 165.32 \\
\hline & 0.10 & 75.81 & 64.95 & 60.93 & 207.56 & 187.89 & 169.10 \\
\hline & 0.20 & 81.04 & 66.07 & 64.04 & 209.36 & 196.08 & 177.22 \\
\hline & 0.30 & 90.67 & 77.77 & 74.66 & 224.54 & 207.60 & 195.85 \\
\hline & 0.50 & 95.47 & 87.52 & 84.66 & 236.50 & 218.73 & 206.29 \\
\hline & 0.60 & 105.96 & 89.98 & 89.65 & & & \\
\hline
\end{tabular}

$[\mathrm{NaCl}]$ : Concentration of $\mathrm{NaCl}$.

with or without urea addition respectively.

\section{2) Effect of urea on persistence length of chitosan}

Table 1 shows persistence length of chitosans (80$100 \% \mathrm{DD})$ ranged from $178 \AA$ to $53.6 \AA$ in different $\mathrm{pH}$ (pH 3-5), different ionic strength $(0 \mathrm{M}$ to $0.6 \mathrm{M} \mathrm{NaCl})$ solutions. The values shown in Table 1 are within the ranges reported in the literatures. Rinaudo and Domard (1989) reported in the absence of electrostatic contribution, persistence length equal to $300 \AA$. Rinaudo et al. (1993) reported intrinsic persistence length of $50 \AA$ and to be independent of DD (90-79\%). Kienzle-Sterzer $e t$ al.(1984) reported total persistence length ranged from 52.25 to $79.55 \AA$ \& between ionic strength of $0.05 \mathrm{M}$ and $0.5 \mathrm{M} \mathrm{NaCl}$, degree of ionization of 0.6 to 0.9 . At the same conditions, electrostatic persistence length were ranged from 0.50 to $23.80 \AA$. Addition of urea did not influence the trends of the changes but affected the absolute values. However, upon the urea additions, the persistence length increasing from 178.0 to $219.4 \AA$ and from 53.6 to $165.3 \AA$ at $80 \%$ DD chitosan in $\mathrm{pH} \mathrm{3}$, $0 . \mathrm{M}$ and $100 \%$ DD chitosan in $\mathrm{pH} 5,0.05 \mathrm{M}$ respectively. The effect of urea addition also nullifyed the effects of ionic strength and $\mathrm{pH}$ because the persistence length of chitosan in $0.6 \mathrm{M} \mathrm{NaCl}$ were equal to or higher than those at $0 \mathrm{M} \mathrm{NaCl}$ and less the difference cause by the effect of DD of chitosan and solution $\mathrm{pH}$.

\section{3) Effect of urea on Smidsrod's stiffness parameter}

Although reports on the Smidsrod's stiffness parameter of chitosans with various DD and solution conditions are relatively rare. Terbojevich et al. (1986) reported $B$ value ranging from 0.043 to 0.091 for chitosans (DD of chitosan between 47.8 to $88.0 \%$ ). Rinnaudo and Domard (1986) reported B value of $5.7 \times 10^{-3}$ for chitosans (DD between 82.5 to $99 \%$ ). Later, Rinaudo et al. (1993) reported $B$ value was estimated to be $0.065 \pm 0.02$ and was independent to the DD of chitosans and solvent conditions. Effect of urea on Smidsrod's stiffness parameter is even rarely explored. Results in Table 2 shown the effect of solution $\mathrm{pH}$ and $\mathrm{DD}$ of chitosan on $\mathrm{B}$ value in solution without urea were more pronounced than those solution containing $4 \mathrm{M}$ urea. It indicated the effects of urea on inter- and/ or intra- hydrogen bond formation which rendered the molecule became rigid (molecule in quasi-globular structure) seems having significant effect on the Smidsrod's stiffness parameter. Although there is no data available concerning the effect of urea on the Smidsrod's stiffness parameter. However, effect of urea on Kuhn segment of chitosans has been reported (Kienzle-Sterzer et al., 1986) . Kuhn segment increased from $7.28 \mathrm{~nm}$ to $12.16 \mathrm{~nm}$ upon urea addition. Frangou et al. (1982) reported stabilizes the structure of xanthan by urea evidence by in aensing is order-disorder transition temperature pehaps by reduction in water activity. 
Table 2. The chain stiffness parameter (B) of chitosan of 80,90 , and $100 \%$ deacetylation in different solution $\mathrm{pH}$ with or without $4 \mathrm{M}$ urea

\begin{tabular}{cccccccc}
\hline $\begin{array}{c}\text { Degree of } \\
\text { decaetylation }\end{array}$ & \multicolumn{3}{c}{$\mathrm{pH}$} & & \multicolumn{3}{c}{$\mathrm{pH}(4 \mathrm{M}$ urea) } \\
\cline { 2 - 7 } \cline { 5 - 8 }$(\%)$ & 3 & 4 & 5 & & 3 & 4 & 5 \\
\hline 80 & 0.103 & 0.127 & 0.183 & 0.021 & 0.023 & 0.028 \\
90 & 0.118 & 0.166 & 0.211 & 0.023 & 0.024 & 0.029 \\
100 & 0.154 & 0.206 & 0.291 & 0.025 & 0.032 & 0.040 \\
\hline
\end{tabular}

$[\mathrm{NaCl}]$ : Concentration of $\mathrm{NaCl}$.

Results of Kienzle-Sterzer et al. (1986) and Frangou et al. (1982) are accord with our finding.

\section{ACKNOWLEDGMENT}

The authors wish to express their appreciation for the financial support from the National Science Council, Republic of China. (Project No: NSC 81-0409-B-019-508)

\section{REFERENCE}

1. Anthonsen, M.W., Varum, K.M., and Smidsrod, O. 1993. Solution properties of chitosans: conformation and chain stiffness of chitosans with different degrees of $\mathrm{N}$-acetylation. Carbohydrate Polymer 22: 193.

2. Berkovich, L.A., Timofeyeva, G.I., Tsyurupa, M.P., and Davankov, V.A. 1980. Hydrodynamic and conformational parameters of chitosane. Polymer Science U.S.R.R. 22(8), 2000-2018.

3. Chen, R.H., Lin, J.H., and Tsaih, T. 1994. Relationship between degree of deacetylation and chain stiffness of chitosan molecule in solution. submitted to Asia-Pacific Chitin And chitosan Symposium, 24-27 May 1994, Universiti Kebangsaan Malaysia, Bangi, Malaysia

4. Chen, R.H., Lin, J.H. and Yang, M.H. 1994. Relationships between chain flexibilities of chitosan molecules and the physical properties of their casted films. Carbohydrate Polym. (in press).

5. Domszy, A.G. and Roberts, G.A.F. 1985. Evaluation of infrared spectroscopic techniques for analysing chitosan. Makromol. Chem. 186: 1671.

6. Errington, N., Harding, S.E., Varum, K.M., and Illum, L. 1993. Hydrodynamic characterization of chitosans varying in degree of acetylation. Int. J. Biol. Macromol. 15: 113.

7. Frangou, S.A. Morris, E.R., Rees, D.A., Richard R.K. and Ross-Murphy, S.B. 1982 moleular arigin of xanthan solution rheology: Effect of urea on chitosan conformation and interactions J. Poly. Sci. (Letters) 20: 531 .

8. Gamzazade, A.I., Sklyar, A.M., Pavlova, S.S.A., and Rogozhin, S.V. 1981. On the viscosity properties of chitosan solutions. Polymer Science U.S.S.R. 23(3): 665 .

9. Kienzle-Sterzer, C., Rodriguez-Sanchez, D., and Rha, C. 1984. Solution properties of chitosan: chain conformation. in "Chitin, Chitosan, and Related Enzyme" ed. by Zikakis, J.P. Academic Press, INC. Orlando, pp 383-393.

10. Kienzle-Sterzer, C., Rodriguez-Sanchez, D., and Rha, C. 1986. Solution behavior of chitosan in diluted solutions: Effect of the intramolecular in-teractions between neighboring segments. in "Chitin in Nature and Technology". Ed. by Muzzarelli, R.A.A., Jeuniaux, C., and Gooday, G.M. Plenum Press, New York,. Pp. 338-343.

11. Lai, S.C. 1979. Food Industries (in Chinese) 11: 23.

12. Lee, V.F.P. 1974 solution and shear propeties of chirin and chitosan. ph. D disseration University of Washington Seattle.

13. Lyubina, S.Y., Strelina, I.A., Nud'ga, L. A.Plisko, Y. A. and Bogatova, I. N.1983. Flow birefringence and viscosity of chitosan solutions in acetic acid of various ionic strengths. Polymer Science U.S.R.R. 25(7): 1694.

14. Moore, G.K. and Roberts G.A.F. 1980 Determination of the degree of $\mathrm{N}$-acetylation of chitosan. Int. J. Biol. Macromol. 2: 115.

15. Pogodina, N.V., Pavlov, G.M., Bushin, S.V., Mel'nikov, A.B., Lysenko, Y.B., Nud'ga, L.A., Marsheva, V.N., Marchenko, G.N., and Tsvetkov, V.N. 1986. Conformational characteristics of chitosan molecules and demonstrated by diffusionsedimentation analysis as viscometry. Polymer Science U.R.S.S. 28(2): 251.

16. Rinaudo, M. and Domard, A. 1989. Solution properties of chitosan in "Chitin and Chitosan. Sources, Chemistry, Biochemistry, Physical Properties and Application". Ed by Skjak-Braek, G., Anthonsen, T. and Sanford, P. Elsevier Applied Science Publishers. N.Y. pp 71-86.

17. Rinaudo, M., Milas, M. and Le Dung, P. 1993. Characterization of chitosan. Influence of ionic strength and degree of acetylation on chain expansion. Int. J. Biol. Macromol. 15: 281. 
18. Sannan, T., Kurita, K. and Iwakura, Y. 1976. Studies on chitin, 2- Effect of deacetylation on solubility. Makromol. chem. 177: 3589.

19. Sklyar, A.M., Gamzazade, A.I.,Rogovina, L.Z., Tifkova, L.V., Pavlova, S.A., Rogozhin, S.V., and Slonimskii, 1981. Study of rheological properties of dilute and moderately concentrated solutions of chitosan. Polymer Science U.S.S.R. A23(6): 1546.

20. Smidsrod, O. and Huag, A. 1971. Estimation of the relative stiffness of the molecular chain in polyelectrolytes from measurements of viscosity at different ionic strengths. Biopolymers, 10: 1213.

21. Stanley, W.L., Watters, G.G., chan, B.G. and Mercer, J.M. 1976. Immobilization of glucose isomerase on chitin with glutaraldehyde and by simple adsorption. Biotech. Bioeng. 18: 439.

22. Terbojevich, M., Cosani, A., Scandola, M., and Fornasa, A. 1986. Solution properties and mesophase formation of chitosan. in "Chitin, Chitosan, and Related Enzymes." Ed. by Zikakis, J.P. Academic Press, Inc. Orlendo. PP 349-351.

23. Wang, W.,Bo, S., Li, S. and Qin, W. 1991. Determination of the Mark-Houwink equation for chitosans with different degrees of deacetylation. Int.J. Biol. Macromol. 13: 281.

24. Yamakawa, H. and Fujii, M. 1974. Intrinsic viscosity of wormlike chains. determination of the shift factor. Macromolecules, 7: 128. 